\title{
A Simplified Approach to Diagnostic Rectal Biopsy in Infants and Children
}

William H. Weintraub, MD, Ann Arbor, Michigan

Kathleen P. Heidelberger, MD, * Ann Arbor, Michigan

Arnold G. Coran, MD, Ann Arbor, Michigan

Since 1948, when Swenson and Bill [1-3] first introduced the concept of using rectal biopsy to definitively diagnose Hirschsprung's disease, Pediatric surgeons have frequently used this procedure in an attempt to differentiate Hirschsprung's disease from other causes of constipation [4-7]. The standard approach is a full thickness biopsy performed transrectally, a technic requiring general anesthesia and hospitalization. In contrast, rectal biopsy done with the suction capsule is safely performed at the bedside or in the office. In addition, the technic is much simpler than operative rectal biopsy [8-16], especially in the small infant. The present study was undertaken in an attempt to evaluate this newer procedure.

\section{Material and Methods}

During the period July 1, 1974 to June 30, 1976, ninety-four patients underwent 103 rectal biopsies with the suction capsule, utilizing the technic described herein. Biopsy was performed for neurologic disorders in twentythree patients and to rule out Hirschsprung's disease in seventy-one patients. During this same two year period, eighteen other infants and children with known Hirschsprung's disease, not included in the study, were managed without suction biopsy since each had had a diagnosis confirmed by full thickness biopsy elsewhere or prior to the institution of the suction technic. Incidental suction biopsies were performed on these patients and each was interpreted as aganglionic.

The $4.7 \mathrm{~mm}$ multipurpose biopsy tube (Quinton Instruments, Seattle, WA) is kept clean but not sterile. After it is assembled (Figure 1), the capsule tip is placed approximately $2.5 \mathrm{~cm}$ proximal to the anal verge with the blade closed. A small amount of lubricant may be used to aid in insertion. The blade is then opened; $15 \mathrm{~cm}$ of suction is applied with the syringe on the side of the instrument and the blade is closed. The entire procedure takes less

From the Section of Pediatric Surgery, and the Department of Pathology*, University of Michigan, Ann Arbor, Michigan.

Reprint requests should be addressed to William H. Weintraub, MD, Mott Children's Hospital, Ann Arbor, Michigan 48109.

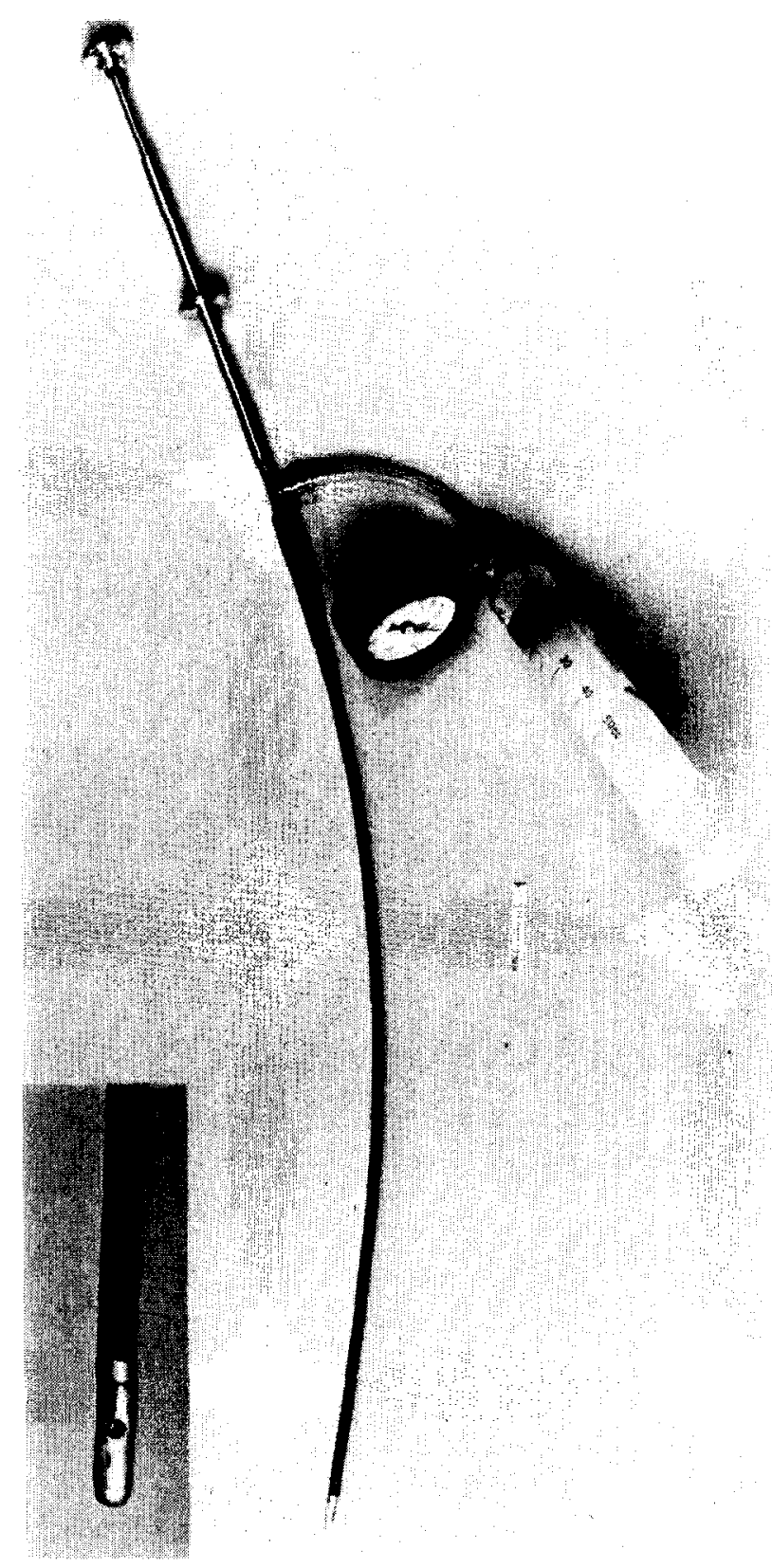

Figure 1. Fully assembled blopsy sef. Insert shows blade housing. 


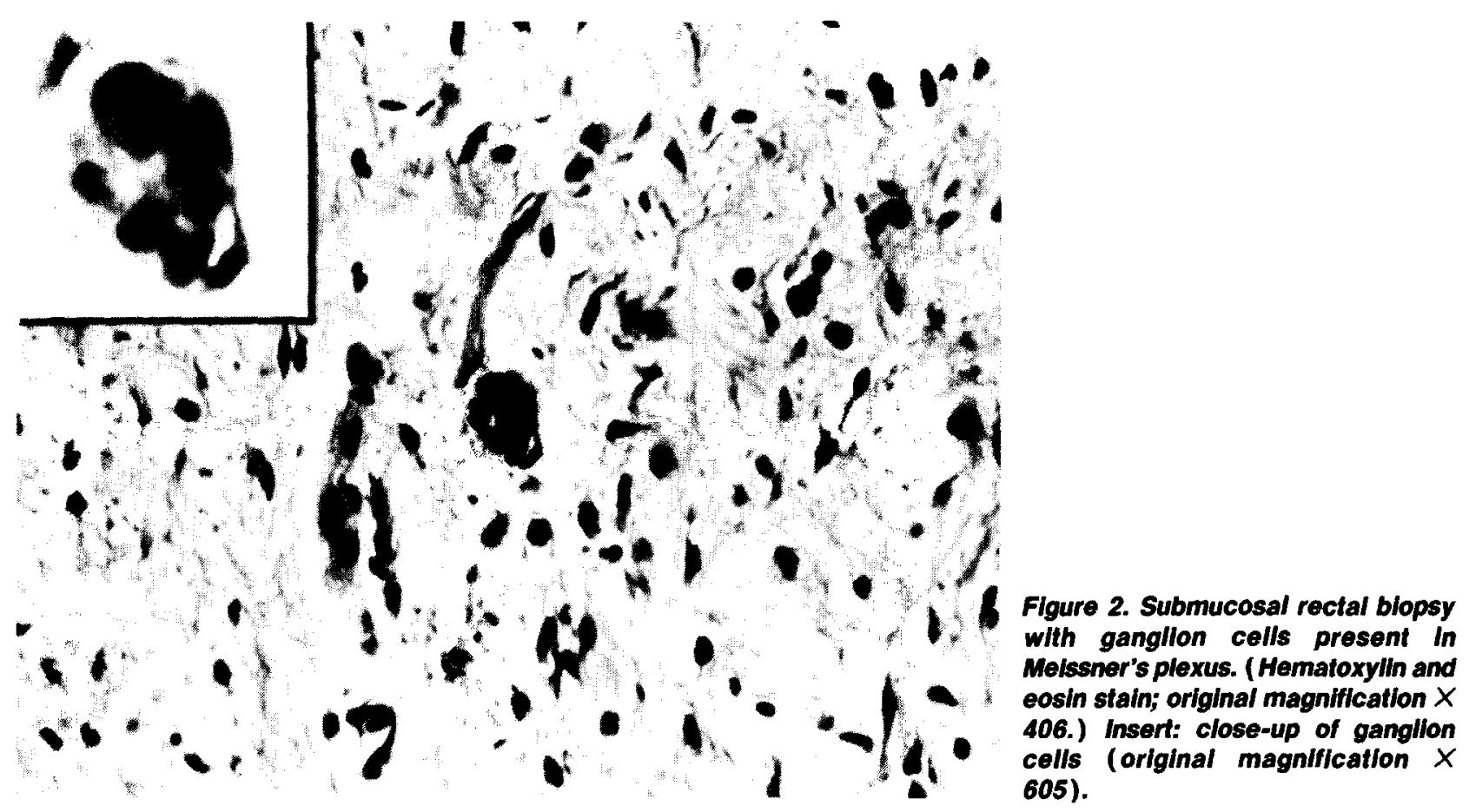

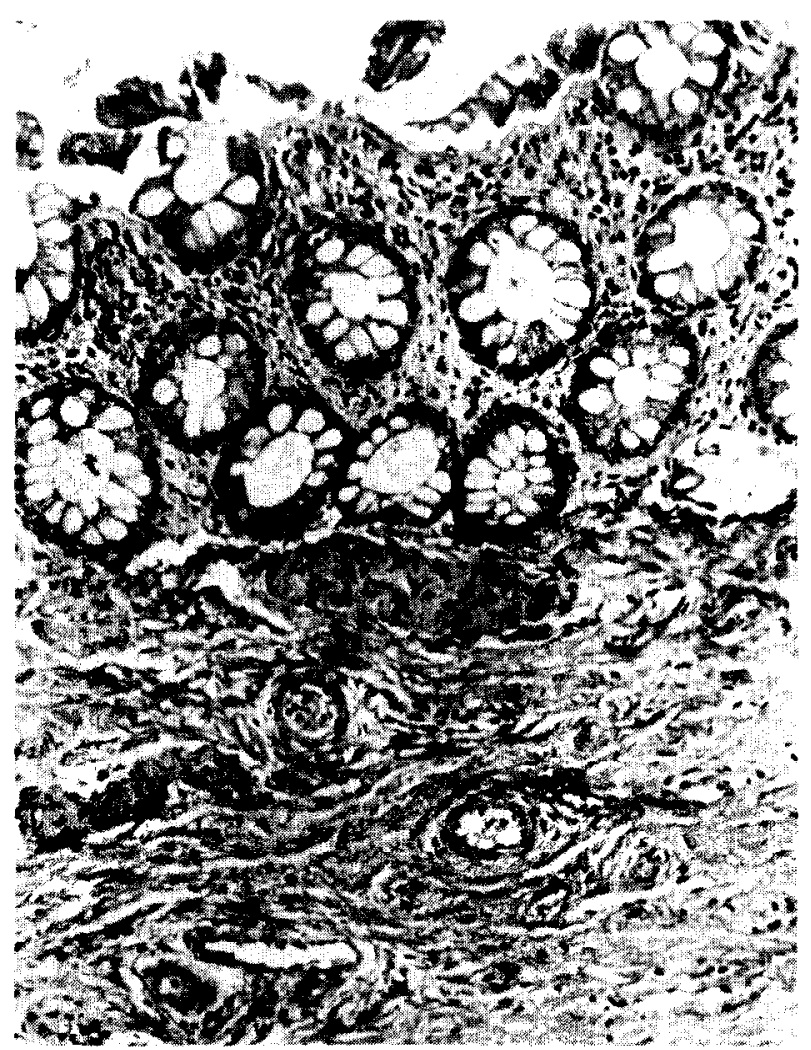

Figure 3. Rectal biopsy without ganglion cells. The prominent submucosal nerves Illustrated are a frequent finding. (Hematoxylin and eosin stain; original magnification $X$ 163.) than 5 seconds. This method produces a round disc of mucosa and submucosa 3 to $4 \mathrm{~mm}$ in diameter and $1 \mathrm{~mm}$ deep. Underlying tissues are not disturbed and no circular or longitudinal muscles are found in the specimen. In children older than two years, the larger rectal ampulla makes it difficult to create the necessary vacuum with the syringe. Therefore, in these patients, the surgeon may need to place a gloved index finger in the rectum and gently press the opened capsule window against the wall of the colon prior to creating suction. Occasionally, a low enema is needed 1 hour prior to biopsy to clean out the ampulla. The procedure is done in the office or in the patient's hospital room.

The specimen is fixed in formalin prior to paraffin embedding, except when special studies are needed for the diagnosis of various neuronal storage diseases. The discs of tissue are easier to orient than full thickness biopsies which are often irregular in shape and contour. The specimen is embedded for sectioning in a plane perpendicular to the submucosa. The entire disc is serially sectioned at $5 \mu$ with approximately twenty sections being placed on each of ten slides.

The slides are stained with routine hematoxylin and eosin and are then examined for ganglion cells in Meissner's submucosal plexus. If ganglion cells are present, they are seen on the first one or two slides that contain adequate submucosa. (Figure 2.) If ganglion cells are absent, all sections on all slides are examined. Large nerves and/or hypertrophied muscularis mucosae are frequently noted in aganglionic biopsies $[17,18]$. (Figure 3.) Special stains for anticholinesterase are not used. 


\section{Results}

The results from the seventy-one patients biopsied to determine the presence of ganglion cells are summarized in Table I. The thirty children less than three months of age were biopsied because of a history of failure to pass meconium in the first 48 hours of life or because of an abnormal barium enema with or without barium retention at 24 hours [19]. Four of these thirty patients had no ganglion cells present in the suction biopsy and were subsequently proved to have Hirschsprung's disease on a seromuscular biopsy performed at the time of colostomy. The twenty-six remaining infants had easily identifiable ganglion cells present, thereby ruling out the diagnosis of Hirschsprung's disease [17,20]. None of these patients has had bowel difficulties or constipation since discharge. In three patients, the biopsy contained only mucosa and a repeat biopsy was required because the first biopsy was not deep enough to reach submucosa.

Eleven patients between three months and two years of age were referred to the hospital for management of suspected Hirschsprung's disease. Eight of these patients had normal suction rectal biopsies and have responded well to a medical regimen for functional constipation. In the other three children, the diagnosis of Hirschsprung's disease was made by suction biopsy and they have subsequently undergone definitive surgery at which time seromuscular biopsy reconfirmed the diagnosis.

Thirty patients older than two years were seen because of chronic constipation. The suction rectal biopsy in twenty-eight of these patients revealed normal ganglion cells, thereby ruling out the diagnosis of Hirschsprung's disease. All of these patients were placed on a regimen for functional constipation, and most responded well. The two patients without ganglion cells have had a colostomy and seromuscular confirmation of Hirschsprung's disease. Six patients in this older age group required a second biopsy because the first specimen was inadequate and contained only mucosa. None of the seventy-one patients underwent a full thickness rectal biopsy.

Twenty-three patients (all older than 2 years) were referred by the Pediatric Neurology Service in an attempt to obtain histologic evidence for or against clinically suspected storage diseases. Ten patients had normal-appearing ganglion cell cytoplasm; in seven patients the tissue was inadequate to determine whether or not the storage of abnormal products was present. Six patients had ganglion cells with cytoplasm swollen by a granular, periodic acid Schiff-negative material, consistent with storage of a nonpolysaccharide material.

\section{Comments}

Pediatric surgeons see a wide variety of infants and children in whom the diagnosis of Hirschsprung's disease must be considered. A barium enema is often nondiagnostic, especially in the neonatal age group [19]. A definitive diagnosis usually requires a rectal biopsy. Full thickness biopsy of the rectum requires general anesthesia and can be technically difficult in the small neonate. The suction biopsy technic is quick, easy, painless, and we believe, highly accurate. Furthermore, because of its simplicity, we tend to use it more frequently than we used the operative technic in the past. Within 24 hours, the ganglion cell status of the patient is known, facilitating, for example, the management of the sick premature who also has other life-threatening disorders that would significantly increase the risk of general anesthesia. For this reason, the technic has been especially helpful in managing newborns with the left colon syndrome $[21]$.

The procedure has also been very helpful in the management of the older child with constipation. During the initial evaluation of the child, a suction biopsy is performed and the question of Hirschsprung's disease is decided within 24 hours. Usually ganglion cells are present and a functional constipation regimen is immediately instituted. If ganglion cells are absent, a diagnosis of Hirschsprung's disease is made and the child prepared for colostomy or definitive pull-through procedure. At the time of laparotomy, a seromuscular biopsy is taken to confirm the absence of ganglion cells.

One major concern at the beginning of the study was whether or not it was possible to accurately diagnose Hirschsprung's disease with this "superficial" mucosal/submucosal biopsy obtained by the suction technic. Obviously on any specimen where ganglion cells are present, Hirschsprung's disease can definitely be ruled out. Experience with aganglionic specimens was gained by our pediatric pathologist (KPH) both as the study progressed and as patients with known Hirschsprung's disease were seen and biopsied in the office. Some biopsies had to be repeated because of insufficient submucosa on the specimen, but ultimately it was possible to prospec-

TABLE I Rectal Blopsy in 71 Pationts to Determine the Presence of Ganglion Cells

\begin{tabular}{cccc}
\hline Age & No. of Patients & \multicolumn{2}{c}{ Ganglion Cells } \\
\hline$<3$ mo & 30 & 26 & 4 \\
3 mo to 2 yr & 11 & 8 & 3 \\
$>2$ yr & 30 & 28 & 2 \\
\hline
\end{tabular}


tively separate all patients into those in whom ganglion cells were seen and those in whom no ganglion cells at all were present in the submucosa.

At the present time we believe that once a pathologist gains experience with this type of biopsy, he or she will read them with the same accuracy as full thickness specimens. The nine patients in our series with aganglionosis each had a colostomy and seromuscular confirmation of the diagnosis of Hirschsprung's disease. None of the other sixty-two children have developed clinical evidence of Hirschsprung's disease to date.

In patients with neurologic disorders, suction rectal biopsy is a quick and safe method for obtaining tissue for histochemical analysis. Abnormal storage products are not frequently found, but the safety and simplicity of the suction rectal biopsy warrant continued application of this technic.

Fortunately, we have had no real complications from this procedure. Nine of our patients-almost all older children with large ampulla and thick mucosa-required a repeat biopsy because of inadequate depth on the original specimen. This problem was obviated by inserting a finger and pressing the capsule against the rectal wall. Repeat biopsy was successful in each of these patients.

An added advantage of the capsule biopsy technic is that it eliminates the scarring that occurs in the rectum between the submucosa and muscularis after a full thickness biopsy. This scarring can make the subsequent submucosal dissection during the Soave procedure [22] much more difficult.

\section{Summary}

During a two year period, ninety-four patients underwent 103 rectal biopsies using the suction capsule technic (71 patients for diagnosis of Hirschsprung's disease and 23 to aid in the diagnosis of various neurologic storage disorders). In nine prospective and eighteen retrospective cases the suction biopsy accurately determined the diagnoses of Hirschsprung's disease. No false-positive or false-negative results were encountered. The technic is simple and safe, requiring neither an operating room nor general anesthesia. No complications were seen after this procedure.

\section{References}

1. Swenson O, Bill AH: Resection of the rectum and rectosigmoid with preservation of the sphincter for benign spastic lesions producing megacolon: an experimental study. Surgery 24: $212,1948$.

2. Swenson $O$ : A new surgical procedure in the treatment of Hirschsprung's disease. Surgery 28: $371,1950$.

3. Fisher JF, De Luca FG, Swenson O: Rectal biopsy in Hirschsprung's disease. Z Kinderchir. 2: 67, 1965.

4. Rowe MI, Clatworthy HW Jr: Rectal biopsy for megacolon. Surg Gynecol Obstet 126: 121, 1968.

5. Swenson O, Neuhauser EBC, Pickett LK: New concepts of the etiology, diagnosis and treatment of congenital megacolon (Hirschsprung's disease). Pediatrics 4: 201, 1949.

6. Swenson O, Fisher JH, MacMahon HE: Rectal biopsy as aid in diagnosis of Hirschsprung's disease. N Engl J Mod 253: 632, 1955

7. Swenson O, Fisher JH, Gherardi GD: Rectal biopsy in the diagnosis of Hirschsprung's disease; experience with one hundred biopsies. Surgery 45: 690, 1959.

8. Campbell PE, Noblett HR: Experience with rectal suction biopsy in the diagnosis of Hirschsprung's disease. J Pediatr Surg 4: 410,1969 .

9. Dobbins WO, Bill AH: Diagnosis of Hirschsprung's disease excluded by rectal suction biopsy. NEngl J Med 272: 990 , 1965

10. Shandling B: A new technique in the diagnosis of Hirschsprung's disease. Can J Surg 4: 298, 1961.

11. Shanding $B$, Auldist $A W$ : Punch biopsy of the rectum for the diagnosis of Hirschsprung's disease, J Pediatr Surg 7: 546 1972.

12. Noblett HR: A rectal suction biopsy tube for use in the diagnosis of Hirschsprung's disease. J Pediatr Surg 4: 406, 1969.

13. Brandborg LL, Rubin CE, Quinton WE: A multipurpose instrument for suction biopsy of the esophagus, stomach, smal bowel and colon. Gastroenterology 37: 1, 1959.

14. Flick AL, Voegtlin KF, Rubin CE: Clinical experience with suction biopsy of the rectal mucosa. Gastroenterology 42 : 691, 1962.

15. Flick AL, Quinton WE, Rubin CE: A peroral hydraulic biopsy tube for multiple sampling at any level of the gastrointestinal tract Gastroenterology 40: 120, 1961.

16. Quinton WE, Flick AL, Rubin CE: The design of a hydraulic suction tube for peroral biopsy of the human gastrointestinal tract. Gastroenterology 42: 281, 1962.

17. Aldridge RI, Campbell PE: Ganglion cell distribution in the normal rectum and anal canal. A basis for the diagnosis of Hirschsprung's disease by anorectal biopsy. J Pediatr Surg 3: 475,1968 .

18. Gherardi GT: Pathology of the ganglionic-aganglionic junction in congenital megacolon. Arch Pathol 69: 520, 1960.

19. Berdon WE, Baker DH: The roentgenographic diagnosis of Hirschsprung's disease in infancy. Am J Roentgenol Radium Ther Nucl Med 93: 432, 1965.

20. Weinberg AG: Hirschsprung's disease - a pathologist's view. Perspectives in Pediatric Pathology, vol 2 (Rosenbery $H$, Bolander, ed). Chicago, Year Book Medical, 1975.

21. Davis WS, Favora BE, Slovis TL: Neonatal small left colon syndrome. Am J Roentgenol 120: 322, 1974.

22. Soave F: Hirschsprung's disease: clinical evaluation and details of a personal technique. Z Kinderchir (Supp): 66, 1966. 